\title{
DE ANTÍGONA A CASANDRA: LOCAS MÍTICAS ENTRE EXCLUSIÓN, SACRIFICIO Y REVELACIÓN
}

\author{
FROM ANTIGONE TO CASSANDRA: MYTHICAL MADWOMEN BETWEEN \\ EXCLUSION, SACRIFICE AND REVELATION
}

Stéphanie Urdician

Université Clermont Auvergne, CELIS (EA 4280)

\section{Resumen:}

La locura femenina abunda en las representaciones del sujeto femenino desde la Antigüedad. El presente trabajo pretende rastrear las modalidades de recepción de dos figuras míticas femeninas en su relación con la locura. Entre el rechazo de los retratos de "locas" transmitidos por la tradición patriarcal y la gestación de un delirio fecundo, este trabajo trata de indagar en el potencial creativo y reivindicativo de la locura en clave femenina.

\section{Palabras claves:}

Antígona, Casandra, delirio, género.

\section{Abstract:}

Female madness abounds in representations of female subject since antiquity. This paper aims to track the reception of two mythical figures in their relationship with madness. Between the rejection of the portraits of "madwomen" transmited by the patriarcal tradition and the creation of a fruitful delirium, this work investigates the creative and protest potential of madness from female perspective.

\section{KEY WORD:}

Antigone, Cassandra, delirium, gender. 


\section{En memoria de Françoise Duroux}

Se puede rastrear el vínculo entre la mujer y la locura desde el patrimonio griego - en las tragedias donde abundan las locas míticas construidas como antítesis del hombre razonado - hasta la cultura popular que lo inscribe en el inconsciente colectivo como lo revela el modismo "a tontas y a locas" que significa, según el DRAE, "hacer una cosa con desbaratamiento, sin orden ni concierto". Carencia de lógica y enajenación aparecen como signos caracterizadores del ente femenino. Por otra parte, la thémis ubica a las mujeres en la esfera doméstica imposibilitando un discurso en el espacio público del ágora. Así es como la mujer cumple los requisitos del duelo en el espacio privado, como bien lo estudió Nicole Loraux en Les mères en deuil (Loraux, 1990). Ahora bien, cuando la mujer transgrede estas fronteras es cuando la tachan de loca. En la mitología hebrea, la figura primigenia de la loca puede ser la primera mujer, Lilith, cuya transgresión ha sido interpretada y transmitida por el poder patriarcal como símbolo de sexualidad depravada, verdadero instrumento político para contrarrestar cualquier forma de rebelión en contra de la ley del padre. Lilith es la mujer mala, la bruja, la loca que se opone a la ley patriarcal y cuyo castigo es la exclusión - exiliada del Edén, excluida de la esfera del saber - Lilith era "la que sabía" según Belial en la Biblia hebrea - y del poder.

La locura ligada a la mujer presenta dos caras en los textos que propongo explorar: la locura como arma masculina frente a la amenaza femenina que desemboca en la marginación del sujeto femenino - recordar con N. Loraux que la "democracia antigua se fundó en la exclusión y la derrota de las mujeres" - y la locura transgresiva que consiste en la resemantización de este espacio y estatuto marginado para fomentar la emancipación de la "loca". Para ilustrar este doble movimiento, me detendré en dos figuras míticas paradigmáticas, Antígona y Casandra, a través de una lectura diacrónica, esto es desde los hipotextos griegos hasta las reescrituras contemporáneas. En ambas trayectorias, la locura, el sacrificio (de la virgen) y la revelación (o "razón" femenina) vertebran los guiones míticos y cuestionan el papel y la ubicación de la mujer tanto en la polis antigua como en las sociedades actuales.

El género de la tragedia conlleva una propensión a exhibir el desvarío como bien lo recalca el trabajo de Simon Bennett que rastrea los orígenes de la psiquiatría moderna en las fuentes griegas: "la descripción de la mente sometida a sus mayores conflictos y perturbaciones ocupa un lugar destacado en el arte trágico" (Bennett, 1984: 106) "abundan los términos referentes a la vida mental, términos que forman parte de una amplia muestra de actividades intelectuales y de una gran variedad de estados sensitivos" (Bennett, 1984: 107). En la Antígona de Sófocles destaca un gran número de términos relativos a la locura: el sustantivo "desatino" cuando Antígona le dice a Ismene: "Si sigues hablando, serás mi enemiga, y yacerás como enemiga, con justicia, para el muerto. Pero permíteme a mí y mi desatino padecer esto que es pasmoso. Pues no me persuadiré de nada tal como para morir ignominiosamente." 1 (v. 90); los adjetivos "loca" en boca de Creonte - "De estas dos muchachas digo que la una se ha vuelto loca desde hace poco, la otra, lo está desde que nació" (Sófocles, 1921: 160) - o "insana": "Creonte: Yo declaro sobre las dos niñas: por un lado, que la una se ha mostrado insana recientemente; por otro lado, la otra lo es desde un principio" (v. 561). Pero esta locura es también "terco genio", sintagma que revela en filigrana el potencial subversivo del gesto de Antígona. No podemos pasar por alto otra réplica tajante de Creonte que bien designa el mayor desafío de su sobrina para entender lo que está en juego: "Creonte: Pero, mientras yo viva, no mandará en mí una mujer" (v. 525), esto es la repartición de las fuerzas masculinas y femeninas en la sociedad tebana. La razón masculina excluye a la mujer del debate denunciando su locura. Esta confrontación emblemática de la tragedia sofoclea da cuenta del contexto histórico de la democracia griega y de su modelo de organización social y sexuada. La respuesta de la princesa tebana invierte la perspectiva enfatizando una rebelión que cuestiona la razón patriarcal: "Antígona: Si ahora te parezco que he obrado como una loca para obtener fortuitamente un beneficio, posiblemente para un loco incurro en la locura" (v. 468-470). En términos de Françoise Duroux, Antigone "met les pieds là où elle [une femme] n’a rien à faire" según lo previsto por "le partage sexuel, soit des limites et des frontières circonscrivant une zone non pas 'hors la loi', mais d'exclusion incluse, qui fait des femmes des 'sujettes', des incapables juridiques" (Duroux, 1993: 77).

En cuanto a Casandra, ella es la extranjera, la loca. Así es como la retratan antes de que salga a escena en Agamenón de Esquilo:

CORIFEO. La extranjera parece que necesita un intérprete lúcido. Sus modales son los de una fiera acabada de coger.

CLITEMNESTRA. Está loca sin duda y sólo escucha sus locos consejos (Esquilo, vv. 1060-1065)

Los coros no hacen sino confirmar esta aserción que aleja a Casandra de la humanidad por ser desprovista de un lenguaje articulado. El de Agamenón dice: “Eres una loca, juguete de los dioses y lloras sobre ti misma un canto destemplado, como el rubio ruiseñor, insaciable de llanto" mientras que el de Las troyanas de Eurípides alude a "la doncella delirante" para comentar la primera réplica de Casandra caracterizada por su "delirio profético".

En ambos casos, "el saltarse visiblemente las normas es la evidencia de la locura" (Bennett, 1984: 107). Además, el origen de la locura radica en una procedencia divina, como en la mayoría de las tragedias donde es un "agente divino" el que lo vuelve loco

1 Todas las citas de Antígona de Sófocles proceden de la traducción de María Inés Saravia, La Plata Editorial de la Universidad de La Plata, 2011

(1855-3625 de Culturas y Literaturas, abril 2016 
al personaje trágico. Antígona defiende "las leyes divinas" cuando Casandra es víctima del don profético de $A_{\text {polo }}^{2}$ y a la vez ménade dionisíaca en la versión euripideana.

En las recepciones contemporáneas de estas figuras, la locura va adquiriendo una fuerza transgresiva, connotada positivamente. Es un motivo recurrente en las reinterpretaciones de Antígona como en la Antígona furiosa de Griselda Gambaro, portavoz de las Locas de la Plaza de Mayo que luchan por la memoria ${ }^{3}$ de los desaparecidos argentinos. La de Henry Bauchau también construye un grito fecundo dirigido a las generaciones futuras. Según el personaje de Richard Demarcy, Antígona sería "una loca positiva":

Acteur 2: Antigone, alors, ce serait une folle positive. Sa force, c'est sa folie. E comme un dieu disait 'le fou est le Clair voyant, celui qui voit le plus clair'. Dans un monde d'ordre absolu, la Folle est donc la plus humaine! Celle dont l'origine est la plus anormale est donc celle qui commet l'acte le plus juste, l'acte que la nature et l'humanité attendent, exigent. (Demarcy, 1994: 15)

En el siglo XX, es la Casandra de Christa Wolf la que va a determinar el renacimiento de la princesa troyana cuya presencia se le impone a la escritora alemana: “Je commençai à lire L'orestie d'Eschyle [...] Cassandre. Je la vis tout de suite. Elle, la captive, me captura [...] elle prit possession de moi... Il me sembla qu'elle était la seule dans cette pièce à se connaître elle-même" (Wolf, 1994) . Cassandra llega a ser por consiguiente modelo del conocimiento de sí misma en los períodos de confusión histórica (en este caso, cuando la crisis relativa al papel de los intelectuales en la República Democrática Alemana). La figura mítica funciona como un faro que guía a la escritora en las turbulencias de la historia individual y colectiva. Esta es también la función de Antígona en la vida y obra de María Zambrano, acompañada por la hija de Edipo en su largo exilio ${ }^{5}$. En ambos casos, las figuras míticas garantizan la transmisión de la memoria y cuestionan el papel social de la mujer. La rehabilitación de la locura oscila entre la reivindicación de una voz propia, en un intento de autodefinición que adopta la forma de una autoterapia en Kassandra de Sergio Blanco, hasta la locura creadora que inventa una

2 A propósito de la locura divina, véase la tipología - locura profética, iniciática, poética, amorosa - elaborada por Platón en el Fedro. Véase también el análisis de los personajes videntes en clave genérica en Nazira Alvarez Espinoza "El silencio femenino en el mito griego de Casandra", Revista de Lenguas Modernas, 19 (2013), pp. 59-60.

3 "Antígona: También se encadena la memoria. Esto no lo sabe Creonte ni su ley." (Gambaro, 1989. 202).

4 Para una aproximación a la figura de Casandra, véase el portentoso trabajo de Véronique LéonardRoques y Philippe Mesnard (dir.), Cassandre. Figure du témoignage (2015).

5 El 28 de enero de 1939, María Zambrano cruza la frontera de los Pirineos para regresar el 20 de noviembre de 1984. Véase Duroux, R.; Urdician S., "Cuando dialogan dos Antígonas: La tumba de Antígona de María Zambrano y Antígona furiosa de Griselda Gambaro (En línea). Olivar, 13(17):

$<$ http://www.memoria.fahce.unlp.edu.ar/art_revistas/pr.5502/pr.5502.pdf> nueva modalidad discursiva desde el territorio de la enajenación, como en el delirio de la Antígona zambraniana.

\section{Una Kassandra QueE}

$K_{a s s a n d r a}{ }^{6}$ (2005) del dramaturgo franco-uruguayo Sergio Blanco propone una "stand up tragedy in broken english" según las palabras del autor, en la que la palabra iterativa saturada de modismos erróneos es signo de un discurso inestable. El monólogo de esta nueva Kassandra, un travesti de los barrios periféricos de "alguna ciudad", está escrito en "el inglés precario de su personaje Kassandra que apenas conoce este idioma, y en el inglés de su autor que lo desconoce por completo. Se trata de una lengua de sobrevivencia tanto para el uno como para el otro." Esta acotación de apertura cuestiona el código ubicando la extrañeza y la marginalización en el seno de la obra. El autorretrato introduce la identidad caleidoscópica del personaje - mítico "You know Kassandra, the Troyan girl." (Blanco, 2005: 3) y actual, la figura de la migrante latino ${ }^{7}$ en los EE.UU. que vive del contrabando de cigarrillos y de la prostitución, como lo revela el vestuario estereotipado "un ajustado vestido de color leopardo, medias negras de rejillas y zapatos rojos de taco alto" (Blanco, 2005: 8).

La Kassandra uruguaya denuncia la versión de su historia escrita por los trágicos griegos, Esquilo y Eurípides, en un episodio basado en la repetición del adjetivo "crazy": "I'm not crazy... I'm Kassandra... But I'm not crazy... Everybody say: Kassandra is crazy... Crazy woman... Dangerous girl... Kassandra is wild... Extreme person... But it is not true... I'm not crazy..." y sigue con no menos de diez ocurrencias. Esta ecolalia manifiesta la versión actual y degradada del delirio antiguo, del discurso críptico de la hija de Hécuba. Kassandra convoca su doble genealogía mítica y contemporánea a través de la típica escena de lectura, mostrando el peso de la cultura culta y popular en la configuración de la figura:

De su cartera extrae un libro, se trata de una antigua edición en griego de Las troyanas de Eurípides. Here... The play... I have with me all time... Yes... I travel all time with the book... Yes... I travel in the world with the book and... And... Wait a moment, please... Wait a moment... I travel with the book and with the mask... De su cartera extrae una máscara de Bugs Bunny (Blanco, 2005: 15-16).

La máscara de Bugs Bunny, símbolo de una cultura de masas hegemónica, instaura un desfase asombroso con el sustrato mítico y satura el monólogo, con no menos de quince ocurrencias. Esta repetición concreta uno de los síntomas de la locura del personaje fetichista que acumula los amuletos: "lentes de sol imitación Dolce \&

6 Edición consultada: Kassandra de Sergio Blanco <www.dramaturgiauruguaya.gub.uy $>$

7 El artículo “Las mujeres en el siglo XXI: los aportes de las migrantes” de Elías Ramírez Rouvalis en el epígrafe orienta la recepción de la obra. 
Gabbana", "un reloj de falsa marca CHANEL, tres prendedores redondos de aluminio (uno del grupo musical ABBA, otro del equipo de fútbol Manchester United, un tercero con el rostro de Bugs Bunny)" (Blanco, 2005: 8). La verborragia que caracteriza a la figura femenina actualiza la escena de mania que la emparentaba con las ménades en Las troyanas de Eurípides enfatizando la clave erótica. Según Elaine Showalter éste es el signo distintivo entre locura masculina y locura femenina dado que ésta tiene "specifically sexual meanings" (Showalter, 1987: 8)요. En efecto, la ambivalencia domina el autorretrato centrado en la sexualidad del personaje queer (Butler, 2005) cuando actualiza los rasgos de la princesa troyana a la vez amante de Apolo, sacerdotisa virgen, víctima de Ayax y botín de guerra-concubina de Agamenón. Ahora bien, en la versión de Sergio Blanco, el origen de la enajenación ya no procede de lo divino sino de lo "demasiado" humano, esto es el sistema capitalista que maltrata a los seres más débiles. La alienación política y social sustituye el arrebato divino. La palabra desemboca en una autoterapia dirigida a un público que hace de (sico)analista como en el "teatro síquico" o "Teatro del Yo" cuyo paradigma puede ser el teatro de Sarah Kane. ¿Así es como se puede entender la abundancia de las fórmulas fáticas que usa Kassandra - "You understand?", "You are understand?", "You know" - asociadas a la repetición de "my friend", "you are my friend". La palabra marginada del personaje encerrado en su soledad define los nuevos retos del diálogo y de la comprensión, crucial en la tragedia de Casandra desde sus orígenes: una voz verídica jamás creída.

En su intento de recuperación de una voz propia - en los pasos de la Kassandra de Christa Wolf que quiere "mit meiner [seiner] Stimme sprechen" - hablar con mi [su] $\mathrm{VOz}$-, el personaje queer cuestiona las normas sociales y el género en la construcción del individuo. Actualiza la hybris relatando sus experiencias sexuales elegidas voluntariamente transgresivas como el incesto con Héctor - y sufridas - víctima del sexo comercializado y de su cliente sadomasoquista $\mathrm{M}$. Flaubert del que depende para poder comer y ayudar a sus hermanas ${ }^{2}$. Oscila pues entre el femininismo prosexo ${ }^{10}$ controvertido - que la sociedad bienpensante designa como enfermedad mental o/y desvarío social - y la denuncia de la violencia de género presente en el mercado del

8 "But it was also at this time that the dialectic of reason and unreason took on specifically sexua meanings, and that the symbolic gender of the insane person shifted from male to female." Además la autora recuerda la interpretación de esta locura femenina por los autores del siglo XVIII que veían a la loca, "the madwoman", como "the victim of parental tyranny and male oppression, and as an object of enlightened sensibility" (Showalter, 1987: 10)

9 “Kassandra: He's crazy... But he pay very, very good... You understand ?... And I need Monsieur Flaubert... Yes... I need money ... Hace un gesto con sus dos manos. Cash... To eat, to sleep, to smok... To live... [...]. I need money... For me and all my sisters... Yes for all my sisters in the world... I give money to my sisters in Filipinas, Zagreb, Europe, South America, New Mexico, Maghreb, Unite State, Iraq..." (Blanco, 2005: 2-13)

10 Véase el manifiesto del feminismo "post-porn punk" de Virginie Despentes: "ce que les femmes ont traversé, c'est non seulement l'histoire des hommes, comme les hommes, mais encore leur oppression spécifique. D’une violence inouïe." (Despentes, 2006: 150). sexoํㅡㄹ Esta Kassandra transgénero supera la representación de la loca, exagerando los rasgos de histeria y ninfomania -enfermedades supuesta y tradicionalmente propias de la mujer - para revelar una entidad paradójica, propia de lo femenino múltiple, "nómade" (Braidotti, 2000), concebido como alternativa a la binaridad. Es la heredera de la Casandra de Eurípides elaborada a partir de la tensión permanente entre un decir alegre y la situación trágica de la mujer reificada, ofrecida a los vencedores ${ }^{12}$. Kassandra pone en escena un drama de la desidentificación frente al cual el personaje lleva a cabo una empresa de reconstrucción biográfica - convocando los discursos ajenos en un palimpsesto intertextual - y autobiográfica - reivindicando su propia versión de la historia ${ }^{13}$. Las resonancias sicoanalíticas del mensaje de este yo polifónico, que busca su identidad en su herencia y en su presente, encubre una depresión latente a la vez que dinamita la dicotomía femenino/masculino, revelando a una figura borderline.

\section{El delirio de Antígona, nueva anagnórisis}

La concepción del delirio en la obra de María Zambrano permite otra incursión interesante en la transgresión femenina fructífera. La figura de Antígona acompaña a María Zambrano desde los años 40 con un primer texto titulado "Delirio de Antígona" (1948), piedra angular de su magnífica pieza La tumba de Antígona (1967). En estos textos, así como en el "Cuaderno de Antígona" (1948) y en "Antígona o de la guerra civil" (1958), se va gestando un sistema poético-filosófico fundado en una nueva modalidad discursiva, impuesta por la realidad socio-histórica: por una parte individual, esto es el desafío que representaba el moverse como "mujer filósofo" en el terreno predominantemente masculino de la filosofía ${ }^{14}{ }_{\llcorner}$por otra parte colectiva, la

11 A propósito de estas posturas radicales y su aporte a la reflexión feminista, véase el trabajo de Michèle Soriano que radica en la separación entre género y sexualidad: “Mon hypothèse serait que les tensions, parfois extrêmes, que nous observons entre le féminisme anti-pornographie et le féminisme pro-sexe nous permettent de mesurer la portée épistémologique de ce débat, nous invitent à rendre compte du féminisme en tant que technologie du genre, et enfin nous engagent à nous confronter aux catégories qui sont en jeu, en tant que limites de la pensée du genre." (2013) <http://revues.univpau.fr/lineas/1101>

12 La actualización de S. Blanco superpone varios contextos contemporáneos, desde las violencias extremas vinculadas con las migraciones económicas y políticas, la dictadura cívico-militar uruguaya (1973-1985) y la tragedia de los desaparecidos: “my father is a missing person”. Esta violencia culmina con el desmembramiento de Kassandra por Clitemnestra, otra loca de los Átridas (“Clitemnestra: He lanzado hace tiempo un grito de alegría, cuando llegó el primer mensajero nocturno de fuego, anunciando la conquista y destrucción de Troya. Y alguien censurándome me dijo: 'Convencida por estas señales de fuego, icrees que Troya ha sido ya destruida? Muy propio es de mujer dejar exaltar así el corazón...' Con tales razones me hacían pasar por loca", Esquilo, Agamenón).

13Esta es una estrategia frecuente en las reescrituras míticas cuyo objeto es la rehabilitación de la figura, a partir de una verdad "desde dentro".

14 Véase Nacer por sí misma (1995) de María Zambrano que reúne ensayos dedicados a figuras femeninas (Antígona, Eloisa, Diótima). 
necesidad de dar cuenta de una experiencia límite ${ }^{15}$, la de la guerra civil y la segunda guerra mundial. Esta modalidad discursiva será el delirio $\frac{16}{}$ y su portavoz Antígona, máxima figura de la transgresión de la norma - la Razón de Estado - y del sacrificio (Dufourmantelle, 2007). De-lirare conlleva la idea de salir de la norma establecida, la inadecuación. En clave siquiátrica, el delirio puede ser un síntoma de psicosis. Ahora bien, en el sistema zambraniano, el delirio consiste en la afirmación de la identidad propia, es el camino que conduce a la conciencia naciente. La conversión del personaje que se da plenamente en La tumba de Antígona pasa por la palabra poética ${ }^{17}$ como lo anunciaba ya María Zambrano en El hombre y lo divino: "el delirio es la fuente primera de donde mana la expresión”, "Convertir el delirio en razón sin abolirlo, es el logro de la poesía" (Zambrano, 1993: 211, 353). Además, el delirio altera el tiempo ensanchando el instante de la tragedia: “No sabemos cuánto tiempo permaneció Antígona delirando entre las cuatro paredes de su tumba. Tampoco es necesario. El tiempo del delirio no se cuenta por los minutos de las clépsidras. Y todo sacrificio trae una alteración en el tiempo" (Zambrano, 2012a: 242). En La tumba de Antígona, la princesa tebana "entra delirando" y reinvidica su voz propia: "yo estoy aquí delirando; tengo voz, tengo voz..." (Zambrano, 2012a: 172).

El punto de partida de la interpretación de Antígona por María Zambrano es el rechazo del desenlace creado por Sófocles: “No; Antígona, la piadosa” tenía que entrar en una "larga galería de gemidos y ser presa de innumerables delirios; su alma tenía que revelarse y aun rebelarse" (Zambrano, 2012a: 241). El objetivo de este delirio es la "reconciliación de la atormentada familia" (Zambrano, 2012a: 243) a cargo de Antígona convertida en receptáculo de todos los crímenes de la familia, "el vaso que en todos los sacrificios aparece" (Zambrano, 2012a: 244). Es el germen de vida de los demás, el alimento vital: "su vida va a derramarse para que los demás se alimenten y vivifiquen" (Zambrano, 2012a: 244). Más allá de la fábula antigua, Antígona orquesta la crisis espiritual que sufre la autora cuando su exilio en la Habana donde escribe el delirio que se corresponde con un momento de máxima angustia. Fue cuando empezó su propio descenso a los ínferos al enterarse de la desaparición de un mundo y su progresivo renacer mediante una indagación en las profundidades de la caverna.

15 Según Virginia Trueba, la palabra de Antígona consiste en un "modo de expresión vinculado a una experiencia - histórica o metafísica - de los límites, la cual no es susceptible de codificarse en un sintaxis o lenguaje ordinarios" (Trueba, 2012: 36).

16 El biógrafo de María Zambrano, Jesús Moreno Sanz, compara los delirios zambranianos con "los dislates" de San Juan de la Cruz (concepción del lenguaje poético que pueda transmitir la experiencia mística infinita). El sueño es otra modalidad privilegiada por la autora para crear un nuevo lenguaje capaz de revelar desde las márgenes. Esta alternancia entre sueño y delirio activa el vínculo etimológico con la locura (elucus).

17 En Las palabras del regreso, María Zambrano publica un texto titulado "El origen del teatro" [1965] donde presenta el teatro como "una especie de delirio, auque sea razonado" (2009: 132).
Como Casandra entre dos culturas, dos idiomas, dos géneros, Antígona se ubica en un espacio intermediario: «en un reino que no es el de la vida ni el de la muerte". Esta atopía es lo que Creonte nombra "locura" (Duroux, 1993: 83). La Antígona zambraniana también en el "Delirio primero" lo erótico que se superpone a lo sacrificial cuando un yo femenino se dirige a un tú masculino en el que se confunden las figuras del novio, del hermano y del padre, recordando el motivo del incesto: "Y yo, víctima no consumida, flor sin fruto, quise venir entre los muertos para que ellos se nutrieran de mí, cuerpo sagrado, no tocado" (Zambrano, 2012a: 250). La sintaxis privilegiada en sus monólogos, basada en formas repetitivas (anáfora, polisíndeton, etc.), la emparenta con la Kassandra de Sergio Blanco, asemejando los monólogos respectivos a letanías. Ahora bien la dimensión cristiana que se desprende de la versión zambraniana resemantiza el papel de lo sagrado y lo divino $\frac{18}{}$ en la tragedia de la heroína. Antígona sale de misma, desnace para acoger a los demás en su seno, renacerlos y "nacer por sí misma". En este recorrido, se oponen Razón fría razonadora, responsable de las barbaries de la historia - las del siglo XX en particular - y Delirio como Razón poética encarnada por Antígona, razón-reacción vital frente al "error" de Sófocles que idea su suicidio. "El hermanar vida y muerte es desnacer sin suicidarse": esta fórmula da la clave de interpretación de la tumba donde Antígona desnace par re-nacer en una subversión del orden de la filiación cuando hace nacer a su propio padre quien le dice:

Edipo: Estás en el lugar donde se nace del todo. Todos venimos a ti, por eso Ayúdame, hija, Antígona, no me dejes en el olvido errando. Ayúdame ahora que voy sabiendo, ayúdame, hija, a nacer (Zambrano, 2012b:190-191)

La respuesta de Antígona vertebra toda la obra: ella es la virgen progenitora, síntesis de las oposiciones - vida/muerte, luz/sombra -, "virginidad creadora" (Zambrano, 2012a: 245) que fomenta la aparición de una luz nueva, el advenimiento de una claridad con función simbólica, como lo revela la repetición del "claro" con valor epifánico heredado de la tradición de la Lichtung heideggeriana ${ }^{19}$. Es en un dilema topográfico - ni fuera ni dentro del bosque sino en el claro que culmina en Claros del bosque (Zambrano, 2011) - donde Antígona va a acoger a otras voces, las de los protagonistas de su tragedia familiar porque no puede morirse sin desentrañar el nudo de la historia, sin entender "la razón de esta sangre" (guerra fratricida). Los delirios de Antígona concebidos por María Zambrano conforman la metamorfosis de la figura que la conduce del abismo de la caverna a la liberación interior en un doble movimiento de descenso a los infiernos y ascensión mística. Pero no sólo se recrea a

18 La muerte de Dios proclamada por Nietzsche (El nacimiento de la tragedia, 1872) prefigura la búsqueda de María Zambrano quien busca y encuentra en la nada, en la experiencia trágica, la posibilidad del ser y su conexión con lo divino

19 Para Heidegger, el hombre que se encuentra en el claro de su Ser hace la experiencia de la alteridad. 
sí misma en una singular automayeutica, sino que cumple con la función catártica de la víctima sacrificial (Girard, 1972) salvando "a toda su estirpe de la remota culpa ancestral que venía arrastrándose como una pesadilla del ser". En esta obra, María Zambrano convierte la locura en creación, la tumba en cuna, escenario del renacer de la loca condenada por Creonte y Sófocles.

Para cerrar este sucinto recorrido, diré que en las reescrituras contemporáneas que recuperan las figuras míticas de Antígona y Casandra, la locura sigue vigente en su doble expresión: delata las violencias que siguen sufriendo las mujeres cuando la disfunción de la sociedad y de las relaciones interpersonales trastorna los comportamientos sociales y síquicos - y también puede cambiar de signo para potenciar la creación y emancipación del sujeto femenino - en un mecanismo de doble transgresión. A partir del espacio y del discurso de la exclusión, de la discordancia y del delirio, estas nuevas princesas tebana y troyana regeneran el gesto y el grito que transgreden las normas para cuestionarlas y construir desde las márgenes una voz propia cuyos gérmenes ya se encontraban en las tragedias griegas. Las experiencias asiliarias y los delirios psicóticos irrumpen en otros avatare ${ }^{20}$ que recalcan, mediante otros recursos, la transgresión y la discordancia como rasgos discriminatorios de las figuras míticas femeninas que oscilan entre mito y realidad, entre locura y razón, en una empresa de reconstrucción múltiple.

\section{REFERENCIAS BIBLIOGRÁFICAS}

Bauchau, H., Journal d'Antigone (1989-1997), Arles, Actes Sud, 1999.

----, Antigone, Arles, Actes Sud, 1997.

Bennett S., Razón y locura en la Antigua Grecia, Las raíces clásicas de la psiquiatría moderna, Felipe

Criado Boado (trad.), Madrid, Akal Universitaria, 1984.

Blanco, S., Kassandra, 2005. Internet. 11-1-16.

$<w w w . d r a m a t u r g i a u r u g u a y a . g u b . u y>$

Braidotti, R., Sujetos nómades, Madrid, Paidós Ibérica, 2000

Butler, J., Trouble dans le genre. Le féminisme et la subversion de l'identité, C. Kraus (trad.), Paris, La Découverte, 2005.

Demarcy, R., Les voyageurs et les ombres, Oedipe, Antigone, sur le chemin, L'Avant-Scène Théâtre, 943 (1994), pp. 5-29.

Despentes, V., King Kong Théorie, Paris, Grasset et Fasquelle, 2006.

Dufourmantelle, A., La femme et le sacrifice. D'Antigone à la femme d'à côté, Paris, Denoël, 2007.

20 La serata a Colono de Elsa Morante (1968), Casandra iluminada (rito de pasaje) de Noemí Frenke (2014). Para una lectura comparada de Kassandra de S. Blanco y Casandra iluminada de N. Frenkel véase S. Urdician, "Cassandre rioplatenses contemporaines: mémoire vive et violence de genre" (Léonard-Roques V., Mesnard Ph., 2015: 299-315).
Duroux, F., Antigone encore. Les femmes et la loi, Paris, Indigo \& côté-femmes éditions, 1993.

Duroux, R., Urdician, S. (eds.), Les Antigones contemporaines (de 1945 à nos jours), ClermontFerrand, Presses Universitaires Blaise Pascal, 2010.

----, “Cuando dialogan dos Antígonas: La tumba de Antígona de María Zambrano y Antígona furiosa de Griselda Gambaro", Olivar, 13(17), (2012) pp. 73-95. Internet. 11-1-16. <http:// www.memoria.fahce.unlp.edu.ar/art_revistas/pr.5502/pr.5502.pdf>

Gambaro, G., Antígona furiosa, Buenos Aires, Ed. De la Flor, 1989.

Girard, R., La violence et le sacré, Paris, Grasset, 1972.

Léonard-Roques, V., Mesnard Ph. (dir.), Cassandre. Figure du témoignage, Paris, Kimé, 2015.

Loraux, N., Les mères en deuil, Paris, Seuil, 1990.

Showalter, E., The female malady. Women, Madness and English Culture, 1830-1980, Londres, Virago Press, 1987.

Sófocles, Sietes tragedias de Sófocles, José Alemany Bolufer (trad.), Madrid, Ed. Sucesores de Hernando, 1921.

Soriano, Michèle, "Représenter la sexualité, repenser le sexe: Pets (2012) d'Albertina Carri", Mekouar-Hertberg (dir.), Les paradigmes Masculin/Féminin sont-ils encore utiles?, Lineas, Université de Pau et des Pays de l'Adour, 2013.

Urdician, S., "Antigone, du personnage tragique à la figure mythique", Léonard-Roques V. (ed.), Figures mythiques, Fabrique et métamorphoses, Clermont-Ferrand, Presses Universitaires Blaise Pascal, 2008, pp. 69-94.

----, "Cassandre rioplatenses contemporaines: mémoire vive et violence de genre", LéonardRoques V., Mesnard Ph. (dir.), Cassandre, figure du témoignage, Paris, Kimé, 2015, pp. 299 315.

Wolf, C., Cassandre. Les prémisses et le récit, Lance A., Lance-Otterbein R. (trad.), Paris, Stock, 1994

Zambrano, M., Claros del Bosque [1977], Mercedes Gómez Blesa (ed.), Madrid, Cátedra, 2011.

----., "El delirio de Antígona", La tumba de Antígona y otros textos sobre el personaje trágico, Virginia Trueba Mira (ed.), Madrid, Cátedra, 2012a, p. 239-251.

---, La tumba de Antígona [1967], La tumba de Antígona y otros textos sobre el personaje trágico Virginia Trueba Mira (ed.), Madrid, Cátedra, 2012b, pp. 141-236.

----, "Cuaderno de Antígona", La tumba de Antígona y otros textos sobre el personaje trágico, Virginia Trueba Mira (ed.), Madrid, Cátedra, 2012c, pp. 267-278.

----, "Antígona o de la guerra civil", La tumba de Antígona y otros textos sobre el personaje trágico, Virginia Trueba Mira (ed.), Madrid, Cátedra, 2012d, pp. 263-266.

---, Nacer por sí misma, Elena Laurenzi (coord.), Madrid, Horas y horas, 1995.

----, El hombre y lo divino, México, Fondo de Cultura Económica, 1993. 
----, “El origen del teatro” [1965], Las palabras del regreso, Mercedes Gómez Blesa (ed.), Madrid, Cátedra, 2009, pp. 131-133. 